\title{
Assessing bioaccessible fractions of arsenic, chromium, lead, selenium and zinc in coal fly ashes
}

\author{
B. Lokeshappa • A. K. Dikshit • Y. Luo • \\ T. J. Hutchinson · D. E. Giammar
}

Received: 1 November 2011/Revised: 29 March 2013/Accepted: 30 April 2013/Published online: 17 May 2013

(C) Islamic Azad University (IAU) 2013

\begin{abstract}
The utility of a physiologically based extraction test for evaluating the bioaccessibility of metals from fly ash in the human gastrointestinal system was evaluated in the present research. Calcium-rich and silica-rich fly ashes collected from eight power plants in India and United States of America were assessed for bioaccessibility for arsenic, chromium, lead, selenium and zinc. The results from the physiologically based extraction test were compared with those from a sequential extraction procedure that is often applied to solid wastes. Based on the physiologically based extraction test results, more than $40 \%$ of the arsenic was found to be bioaccessible for all the ashes while selenium was very accessible for the calcium-rich ashes. Lead was found to be insignificantly bioaccessible in calcium-rich as well as silica-rich fly ashes. The
\end{abstract}

B. Lokeshappa · A. K. Dikshit ( $)$

Indian Institute of Technology Bombay, Centre for

Environmental Science and Engineering, Powai,

Mumbai 400076, India

e-mail: dikshit@iitb.ac.in

B. Lokeshappa

Department of Civil Engineering, University BDT College, Davangere 577 004, India

\section{A. K. Dikshit}

School of Civil Engineering, Survey and Construction, University of KwaZulu-Natal, Durban 4041, South Africa

\footnotetext{
A. K. Dikshit

School of Civil and Environmental Engineering, Nanyang

Technological University, Singapore 639798, Singapore

Y. Luo - T. J. Hutchinson - D. E. Giammar

Department of Energy, Environmental and Chemical

Engineering, Washington University, Saint Louis,

MO 63130, USA
}

mobilization of metals in the first three steps of the sequential extraction procedure was similar to the mobilization in the physiologically based extraction test for selenium for all ashes and for arsenic and chromium for most ashes, but the sequential extraction procedure mobilized more zinc than did the physiologically based extraction test. These results indicate that while sequential extraction procedures can provide good estimates of the bioaccessibility of many elements, extraction tests that more closely simulate physiological conditions can provide more accurate measures of bioaccessible concentrations of metals.

Keywords Bioaccessibility · Coal fly ash · Leaching . Metals · Physiologically based extraction $\cdot$ Sequential extraction procedure

\section{Introduction}

About $40 \%$ of global electricity is generated from coalfired thermal power plants that consume over 5 billion tons of coal (Mukherjee et al. 2008) and produce more than 700 million tons of coal fly ash each year (Prakash and Sridharan 2009). In addition to impacts of coal-fired power plants on air quality through atmospheric emissions, the generation of metal-rich fly ash poses additional environmental concerns. Increasing coal consumption in thermal power plants implies increased emission of metals in gaseous forms and in the form of fly ash (Kim et al. 2002; Vassilev and Vassileva 2005). The toxic metals that are naturally present in coal are enriched in the coal fly ash as a result of combustion. $\mathrm{As}, \mathrm{Pb}, \mathrm{Se}, \mathrm{Cr}, \mathrm{Ni}, \mathrm{Cd}, \mathrm{Zn}$ and $\mathrm{Hg}$ are common potentially harmful elements carried by coal fly ash (Dayan and Paine 2001; Sonmez and Pierzynsk 2005). 
The availability and the mobility of metals occurring in coal fly ash depend on the physicochemical forms of the metals (Smeda and Zyrnicki 2002), and the total metal contents of the ash are generally poor predictors for the leachable concentrations of the metals (Thorneloe et al. 2010). The environmental conditions as well as the physical and chemical properties of the coal fly ash have a great impact on the mobility of coal fly ash constituents. The metal-related risks associated with coal fly ash should not be determined by the total metal concentrations in the fly ash but rather by the fractions that may be mobilized (i.e., leached) in aquatic systems. Metal mobility can be affected by changes in $\mathrm{pH}$, redox potential, ionic strength and the presence of complexing agents (Popovic and Djordjevic 2009). Metal speciation is influenced by the mechanisms of metal association with the coal fly ash, which include chemical and physical adsorption, precipitation and encapsulation.

There are several metals that may be readily bioavailable, which leads to growing environmental concerns regarding fly ash disposal and utilization (Singh 2005). The bioaccessibility means the amount of metal and metalloids is mobilized and hence, become available to human body under different exposure conditions and environment. For example, the amount of metal that is available for absorption after indigestion is a key parameter in estimating potential human exposure. Various extraction processes are used to determine the potential for metal release from solids at specific environmental conditions to classify materials as hazardous, and to assess metal bioaccessibility. The toxicity characteristic leaching procedure (TCLP) is extensively used in the United States to classify materials as hazardous or non-hazardous based on the extent of leaching of toxic constituents from the material. There are sequential extraction procedures, which can be used to infer mechanisms of metal binding to coal fly ash (Kosson et al. 2002; Worathanakul et al. 2008). These have been used in various forms to determine the amounts of metals in fly ash that are water soluble, ion exchangeable and other extractable forms (Huang et al. 2007). In addition, physiologically based extraction procedures have been proposed specifically to quantify human exposure to toxic metals and metalloids via the oral ingestion pathway.

Physiologically based extractions have been applied to different metal-containing solids to assess the bioaccessibility of metals when the solids are in contact with solutions designed to simulate the human gastrointestinal tract. The physiologically based extraction test (PBET) was developed by Ruby et al. (1996) to simulate the behavior of material in the stomach and the small intestine by providing the appropriate $\mathrm{pH}$, solid-to-liquid ratio and mixing and emptying rates. The PBET is a two-step test that uses hydrochloric acid, pepsin, tri-sodium citrate, sodium malate, lactic acid and acetic acid mixture to simulate the stomach environment with 1 -h residence time and a neutralized solution containing additional bile salt and pancreatin compounds to simulate the small intestine with 2-h residence time (Ruby et al. 1996). Wragg and Cave (2002) demonstrated the PBET as a practical methodology for in vitro measurement of the bioaccessibility of metals and metalloids. The PBET has been applied to soils, mussel tissues, airborne dusts, mine-waste contaminated soils, mining wastes and magnetic fractions of coal fly ashes (Bruce et al. 2007; Roe and Klinck 2007; Wragg et al. 2007; Navarro et al. 2008; Lu et al. 2009; Sialelli and Urquhart 2010).

The objective of the present study work was to assess the bioaccessibility of significant trace elements in coal fly ash through the use of a physiologically based extraction test. The extraction method was applied to a range of coal fly ashes from the thermal power plants in India and in the United States that differed in their origin and physical and chemical properties. The research was conducted at Washington University, USA from September 2010 to December 2010 and at IIT Bombay, India from July 2009 onwards till date.

\section{Materials and methods}

\section{Materials}

Three fly ashes (IN-A, IN-B and IN-C) from three fullscale Indian power plants and five fly ashes (US-A, US-B, US-C, US-D, and US-E) from five U.S. power plants were collected from hoppers of the electrostatic precipitators. All fly ash samples were sieved to finer than $250 \mu \mathrm{m}$ before experiments. The fly ashes were analyzed by powder X-ray diffraction (Rigaku Geigerflex, Japan) to identify the crystalline phases present in the fly ash for physical characterization of its mineralogy. All the fly ash samples were evaluated for their mineralogical compositions by the above XRD spectrometer with graphite monochromator and $\mathrm{Cu}-\mathrm{K} \alpha$ radiation. The samples were scanned from $2 \theta$ of $0^{\circ}-180^{\circ}$.

Ultra pure water produced by Millipore ultrapure water kit (Milli-Q Academic, USA) was used for washing of glassware and preparation of reagents. Ammonium nitrate, acetic acid, sodium dithionite, sodium citrate, sodium bicarbonate, and concentrated nitric acid and hydrochloric acid were used to prepare extractants for the sequential extraction procedure. Pepsin, sodium malate, sodium citrate, lactic acid, acetic acid, bile salt and pancreatin were used for the preparation of stomach and intestinal fluid for use in the PBET. Nitric acid, hydrochloric acid and acetic acid were trace metal grades. All chemicals were of 
analytical reagent grade and were purchased from Fisher Scientific (Pittsburgh, USA). A mutli-element custom standard (ICSU-2726) from Ultra Scientific Analytical Solutions (N. Kingstown, USA) was used for calibration of the inductively coupled plasma mass spectrometer (ICPMS). An aliquot of this standard was also used as control during the experiments.

\section{Methods}

\section{Sequential extraction procedure}

The sequential extraction procedure (SEP) used here has been modified from that proposed by Noel et al. (2007) and is shown in Fig. 1. The fly ashes were subjected to the following five steps: (1) ultrapure water was used to extract water soluble metals; (2) $1.0 \mathrm{M}$ ammonium nitrate was used to remove ion exchangeable metals; (3) $0.11 \mathrm{M}$ acetic acid targeted acid soluble metals; (4) a solution of $0.128 \mathrm{M}$ sodium dithionite, $0.3 \mathrm{M}$ sodium citrate and $0.1 \mathrm{M}$ sodium bicarbonate was used to remove reducible metals; and (5) finally a 4:1 mixture of concentrated nitric acid and hydrochloric acid at $100{ }^{\circ} \mathrm{C}$ in Hot Block (Environmental Express, USA) dissolved the remaining solids. Based on optimization tests carried out at $30 \mathrm{rpm}$ in a specifically fabricated end-over-end mixer, a solid-to-liquid ratio $(1: 100)$ of $0.5 \mathrm{~g} \mathrm{ash} / 50 \mathrm{~mL}$ extractant $(10 \mathrm{~g} / \mathrm{L})$ was used. The optimum agitation times were found to be $24 \mathrm{~h}$ for the acid soluble and reducible steps, while $4 \mathrm{~h}$ was optimum for the remaining steps. $0.5 \mathrm{~g}$ ash was mixed with $50 \mathrm{~mL}$ extractant in $100-\mathrm{mL}$ centrifuge tube for the prescribed time at $30 \mathrm{rpm}$. After agitation, the suspension was centrifuged for $10 \mathrm{~min}$ at $10,000 \mathrm{rpm}$. Nearly, all of the supernatant was decanted and filtered with a $0.2-\mu \mathrm{m}$ PTFE filter. The supernatant was acidified to $2 \%$ (by mass) by adding required nitric acid. The solids remaining from the centrifugation were then gathered with the next extractant in the sequence. Concentrations of metals of interest in various acidified samples were obtained using ICP-MS.

\section{Physiologically based extraction test}

The various parameters for conducting the PBET, viz. gastric and intestine $\mathrm{pH}$, sample mass-to-fluid ratio, stomach mixing, stomach emptying rate and intestinal transit rates, were chosen on the basis of previous studies (Ruby et al. 1996, 1999; Hamel et al. 1998; Rodriguez et al. 1999; Roe and Klinck 2007; Wragg et al. 2007; Sialelli and Urquhart 2010). The details of PBET procedure are shown in Fig. 2. $1.0 \mathrm{~g}$ fly ash was taken in 250-mL I-CHEM certified glass bottle. In the first step, which is to simulate the stomach phase, $100 \mathrm{~mL}$ gastric solution (a mixture of $1.25 \mathrm{~g}$ pepsin, $0.50 \mathrm{~g}$ sodium malate, $0.50 \mathrm{~g}$ sodium citrate,
$420 \mu \mathrm{L}$ lactic acid and $500 \mu \mathrm{L}$ acetic acid made up to $1 \mathrm{~L}$ with freshly prepared ultrapure water, adjusted to $\mathrm{pH} 2.5$ with concentrated hydrochloric acid) was added to each bottle, thus maintaining solid-to-liquid ratio of 1:100. The suspension was agitated at $30 \mathrm{rpm}$ at $37{ }^{\circ} \mathrm{C}$ in a controlled water bath in a PBET setup fabricated as per EPA (2008). A period of 1-h contact was provided to simulate the typical residence time of solids in the stomach. At the conclusion of this hour, a $5 \mathrm{~mL}$ stomach sample was drawn from the bottle. Equivalent amount $(5 \mathrm{~mL})$ of stomach phase gastric solution was replaced to the bottle. After the stomach phase, bile salt $(70 \mathrm{mg} / 100 \mathrm{~mL})$ and the pancreatin $(50 \mathrm{mg} / 100 \mathrm{~mL})$ were added to each bottle and the $\mathrm{pH}$ was adjusted to 7.0 with saturated sodium bicarbonate solution to simulate the small intestinal conditions. Intestinal samples $(5 \mathrm{~mL}$ each) were collected during the small intestinal phase after 3 and $5 \mathrm{~h}$ and are referred to as intestinal phases 1 and 2. Extracted samples were centrifuged for $10 \mathrm{~min}$ at $10,000 \mathrm{rpm}$. The supernatant was filtered with $0.2-\mu \mathrm{m}$ PTFE filter and then acidified to $2 \%$ (by mass) $\mathrm{HNO}_{3}$. The concentrations of metals of interest in stomach, intestinal phases 1 and 2 samples were analyzed using ICP-MS. The higher of the two metal values in intestinal phases 1 and 2 samples was taken as metal extracted in intestine phase.

The bioaccessible fraction is the amount of the element in the ash that can be solubilized in the solutions representing either the stomach or small intestine. The percentages of metal leached in the simulated human gastrointestinal environment of stomach and intestine phases were calculated (Roe and Klinck 2007) as follows:

$$
\begin{aligned}
& \text { Bioaccessible factor } \\
& =\frac{\text { Metal extracted in stomach/intestine phase }}{\text { Total extractable metal }} \times 100
\end{aligned}
$$

where total extractable metal is the maximum metal that can be directly extracted by acid digestion, that is, $0.5 \mathrm{~g}$ fly ash digested with $4: 1$ mixture of concentrated nitric acid $(10 \mathrm{~mL})$ and hydrochloric acid $(2.5 \mathrm{~mL})$ at $100{ }^{\circ} \mathrm{C}$ in $\mathrm{Hot}$ Block for $4 \mathrm{~h}$.

\section{Determination of metals concentrations}

Concentrations of trace metals in samples from SEP and PBET were obtained using an Agilent ICP-MS (Model 7500ce, USA). Prior to analysis, the samples were diluted with $2 \% \mathrm{HNO}_{3}$ solution. Samples from the SEP were diluted 1:10 for the water soluble step, 1:20 for the acid soluble step and 1:50 for the other three steps. PBET samples used a 1:10 dilution factor. Calibration standards were analyzed in the same matrices as the samples. 
Fig. 1 Sequential extraction for assessing the leaching potential of metals

Fig. 2 Extraction of toxic metals by physiologically based extraction test

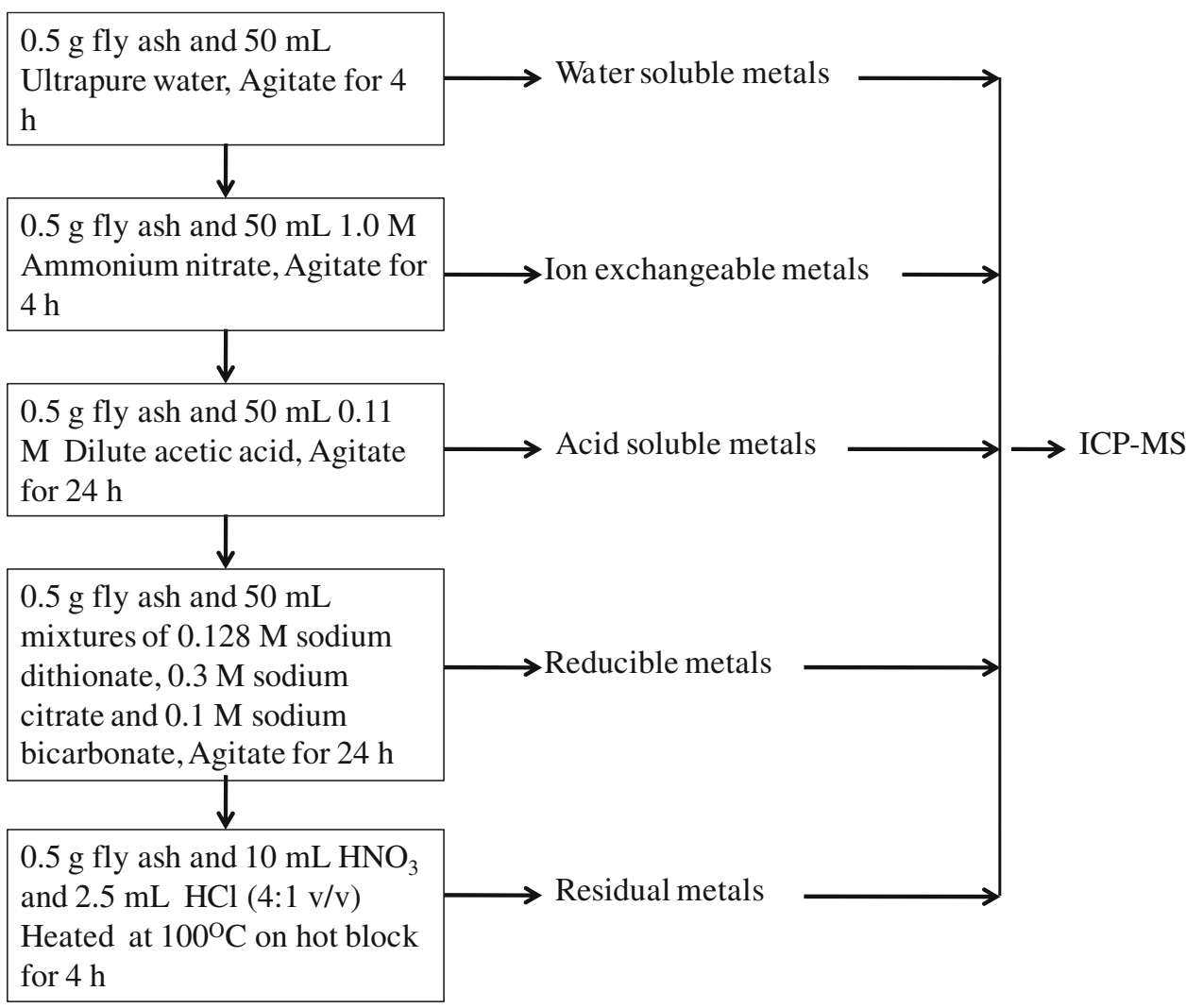

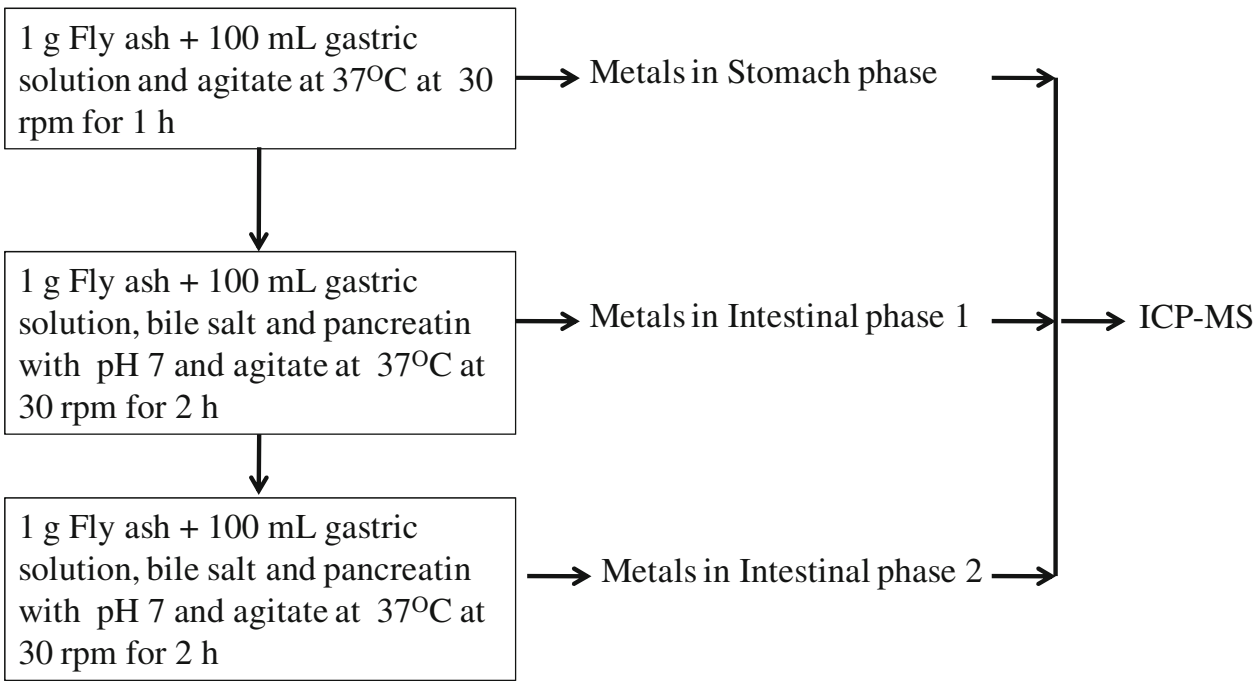

minimum detectable limit for the metals ranged from $0.01 \mathrm{ppb}$ for minor metals to $1 \mathrm{ppb}$ for major metals.

\section{Results and discussion}

Indian and the U.S. coal fly ash properties

Two power plants in India are using bituminous coal mined from Indian coal fields while one is using sub-bituminous coal imported from Indonesia. The ash content of 
Indonesian coal was about $1.9 \%$ while that of Indian coals was 25 and $38 \%$, respectively. Usually coal fly ashes are classified as class $\mathrm{C}$ and class $\mathrm{F}$ based on their calcium oxide contents. Class $\mathrm{C}$ ashes are calcium-rich with greater than $10 \%$ calcium oxide while class $\mathrm{F}$ ashes are siliconrich having less than $10 \%$ calcium oxide. Coal fly ash IN$\mathrm{B}$ is class $\mathrm{C}$ ash being calcium-rich while IN-A and IN-C are silica-rich class $\mathrm{F}$ ash.

The U.S. power plants all use Powder River Basin subbituminous coals that typically have 4-7\% ash content (WGS 2011). All five of the U.S. ashes are class $C$ ashes. The crystalline phases present in the fly ashes are shown in Fig. 3 while Table 1 shows mineralogy and composition of all fly ashes.

Metals extracted in sequential extraction procedure and physiologically based extraction test

The SEPs were carried out for 25 major and minor metals present in all the eight fly ash samples. On the basis of the concentrations, five metals viz. arsenic, chromium, lead, selenium and zinc were found to be the most significant, and hence these five elements were evaluated for bioaccessibility for assessing human exposure by accidental or otherwise ingestion.

Leaching and dilution of toxic metals in the simulated conditions and residence time of acidic stomach phase and the neutral intestinal phase were dependent on the form of metals present in the coal fly ash. Significant amount of metals solubilization taking place in the stomach phase and the intestinal phase environment was strongly depended upon the $\mathrm{pH}$ of the gastrointestinal fluid, presence of calcium, silica and other minerals oxides present in the coal fly ash. The results from PBET were compared with the first 3 steps of SEP results, which are very similar to the TCLP. The total metal extracted through acid digestion was considered as the total extractable metal. Finally, bioaccessible fractions for various metals were determined in using Eq. (1). The results are shown in Fig. 4a-e and are discussed below for each of the five metals.
Fig. 3 Crystalline phases present in a Indian fly ashes and b the U.S. fly ashes

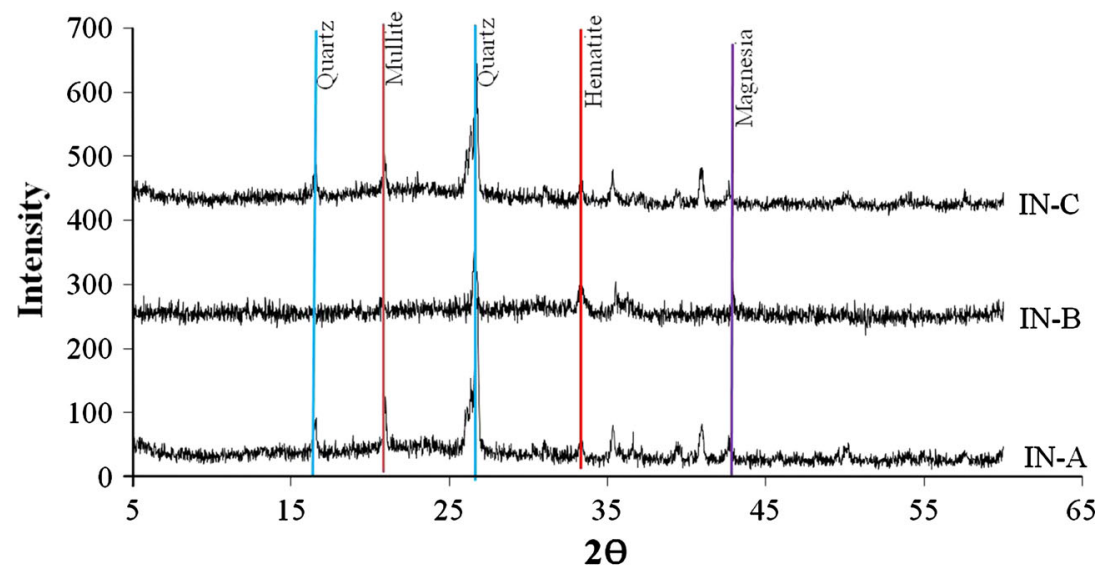

(a)

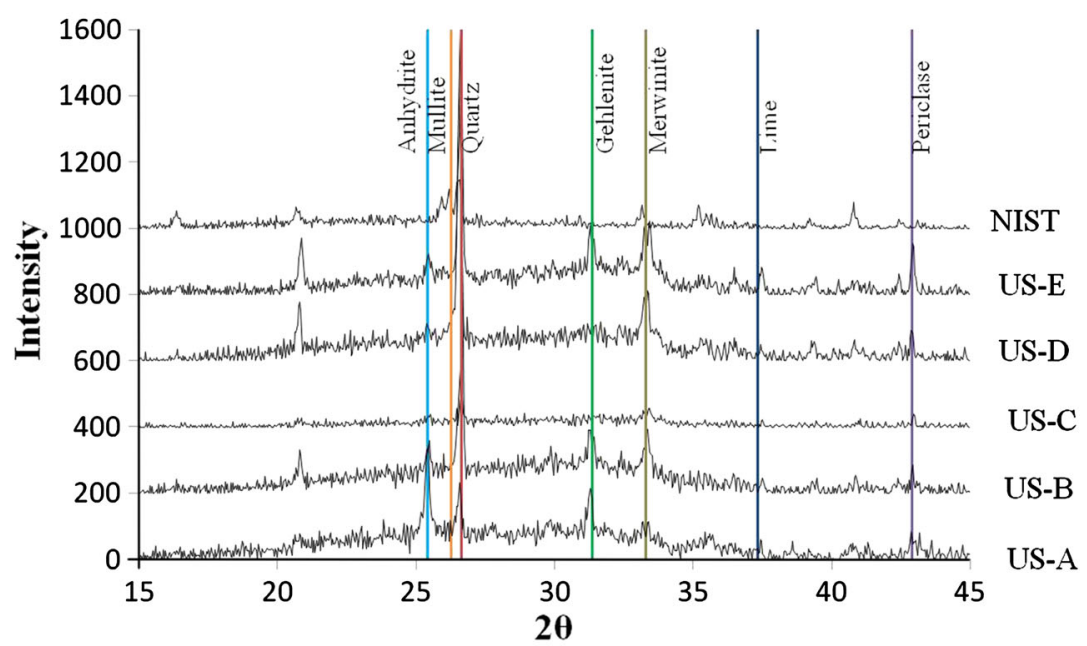

(b) 
Table 1 Composition and mineralogy of fly ash materials studied

\begin{tabular}{|c|c|c|c|c|c|c|c|c|}
\hline Fly ash & LOI $(\%)^{\mathrm{a}}$ & As $(\mu \mathrm{g} / \mathrm{g})$ & $\mathrm{Cr}(\mu \mathrm{g} / \mathrm{g})$ & $\mathrm{Pb}(\mu \mathrm{g} / \mathrm{g})$ & $\mathrm{Se}(\mu \mathrm{g} / \mathrm{g})$ & $\mathrm{Zn}(\mu \mathrm{g} / \mathrm{g})$ & Ash class & Major minerals \\
\hline IN-A & 1.4 & 12.8 & 11.5 & 8.0 & 31.0 & 73.2 & $\mathrm{~F}$ & Quartz, mullite \\
\hline IN-B & 1.1 & 52.9 & 39.3 & 28 & 17.5 & 204.8 & $\mathrm{C}$ & Quartz, magnesia, hematite \\
\hline IN-C & 1.6 & 6.1 & 3.2 & 4.6 & 23.4 & 64.0 & $\mathrm{~F}$ & Quartz, mullite \\
\hline US-A & 17.5 & 22.7 & 64.9 & 43.5 & 15.0 & 230.3 & $\mathrm{C}$ & $\begin{array}{l}\text { Anhydrite, quartz, gehlenite, merwinite } \\
\text { periclase, lime }\end{array}$ \\
\hline US-B & 0.3 & 24.1 & 82.2 & 33.1 & 7.4 & 218.0 & $\mathrm{C}$ & $\begin{array}{l}\text { Anhydrite, quartz, gehlenite, merwinite } \\
\text { periclase, lime }\end{array}$ \\
\hline US-C & 0.7 & 26.9 & 85.3 & 38.0 & 14.5 & 332.7 & $\mathrm{C}$ & $\begin{array}{l}\text { Anhydrite, quartz, merwinite, periclase, } \\
\text { lime }\end{array}$ \\
\hline US-D & 1.6 & 25.1 & 62.8 & 24.0 & 10.1 & 45.0 & $\mathrm{C}$ & $\begin{array}{l}\text { Anhydrite, quartz, merwinite, periclase, } \\
\text { lime }\end{array}$ \\
\hline US-E & 0.4 & 21.4 & 64.3 & 28.2 & 13.5 & 34.1 & $\mathrm{C}$ & $\begin{array}{l}\text { Anhydrite, quartz, gehlenite, merwinite } \\
\text { periclase, lime }\end{array}$ \\
\hline
\end{tabular}

${ }^{\text {a }}$ LOI is loss on ignition, which represents the unburned carbon content in the fly ash samples

\section{Arsenic}

Potentially As leaching took place in the acidic environment in the case of Ca-rich fly ash because $\mathrm{pH}$ of the leaching solution was 2.5 . The percentages of leaching of As in the case of Ca-rich coal fly ash ranged from 40 to $57 \%$ (Fig. 4a). In the Si-rich coal fly ash, As leaching took place in the intestinal phase 1 at $\mathrm{pH} 7$ in the neutral environment of the system. Here, redox reactions occurred in neutral environment of the system due to As bound with oxides and hydroxides in the silicon content of the coal fly ash. As mineral solubilities vary widely according to arsenic oxidation state. As leaching in the intestinal phase of the Si-rich coal fly ash depended on the $\mathrm{pH}$, concentration of the bile salt and the pancreatin solution present in the gastric solution and ranged between 64 and $100 \%$.

In Ca-rich coal fly ash, As leaching from the stomach phase were in the range of $12-21 \mu \mathrm{g} / \mathrm{g}$ of ash whereas the three-step SEP As leaching were 1-17 $\mu \mathrm{g} / \mathrm{g}$ of the ash and the $23-53 \mu \mathrm{g} / \mathrm{g}$ of ash as total As.

For most of the ashes, the greatest amounts of As were leached from the ash in the acidic environment of the PBET. With only one exception (IN-C), the PBET extracted more As than did the 3-step SEP. The difference is particularly striking for the U.S. ashes D and E. The regulatory TCLP test, which is similar to the 3-step SEP, may underestimate the bioaccessibility of As in fly ash. As adsorbs well to iron oxides in mildly acidic solutions, so the mobilization of As in the PBET may be driven more by effects of the organic components of the extraction solutions than by the acidity of the solutions. A recent X-ray absorption spectroscopy of the five U.S. ashes determined that the As was primarily $\mathrm{As}(\mathrm{V})$ and largely present as calcium pyroarsenate $\left(\mathrm{Ca}_{2} \mathrm{As}_{2} \mathrm{O}_{7}\right)$ (Luo et al. 2011). As release during the PBET may be controlled by dissolution of this phase.

\section{Chromium}

As seen from Fig. 4b, the significant amount of $\mathrm{Cr}$ leaching (10-55\%) took place in the stomach phase for the Ca-rich coal fly ash. This is due to the formation of soluble species stable at acidic $\mathrm{pH}$ environment and $\mathrm{Cr}$ co-adsorbed with iron oxide mineral substrate. In Si-rich coal fly ash, the $\mathrm{Cr}$ leaching occurred in the intestinal neutral environment of the gastric solution. This is due to the solubilization of $\mathrm{Cr}$ in the neutral $\mathrm{pH}$ condition. It ranged from 43 to $59 \%$.

The 3-step SEP results of the Ca-rich coal fly ashes ranged from 9 to $30 \mu \mathrm{g} / \mathrm{g}$ of ash whereas in case of Si-rich coal fly ash, these were in the range of $0.4-3 \mu \mathrm{g} / \mathrm{g}$. Total $\mathrm{Cr}$ amounted from 11 to $13 \mu \mathrm{g} / \mathrm{g}$ in the case of Ca-rich coal fly ash whereas in silica-rich coal fly ash, the same ranged between 18 and $58 \mu \mathrm{g} / \mathrm{g}$ of ash.

More $\mathrm{Cr}$ leaching took place from the Ca-rich ashes (U.S. ashes and IN-B), which is consistent with their substantially greater $\mathrm{Cr}$ contents. The mobility and toxicity of $\mathrm{Cr}$ are strongly dependent on the oxidation state, $\mathrm{Cr}$ (III) versus $\mathrm{Cr}(\mathrm{VI})$, but unfortunately no measurements of the Cr oxidation state were available. $\mathrm{Cr}(\mathrm{VI})$ is present as anionic species $\left(\mathrm{HCrO}_{4}{ }^{-}\right.$and $\mathrm{CrO}_{4}^{2-}$ ) and is much more toxic than $\mathrm{Cr}(\mathrm{III})$. Since the pattern of $\mathrm{Cr}$ results is not very similar to that of As, which is present as anionic arsenate for the ashes, it may indicate that the $\mathrm{Cr}$ is present as $\mathrm{Cr}(\mathrm{III})$ and not $\mathrm{Cr}(\mathrm{VI})$.

\section{Lead}

$\mathrm{Pb}$ leaching took place in the stomach phase of the Ca-rich coal fly ash due to the release of $\mathrm{Pb}$ in the gastric solution 


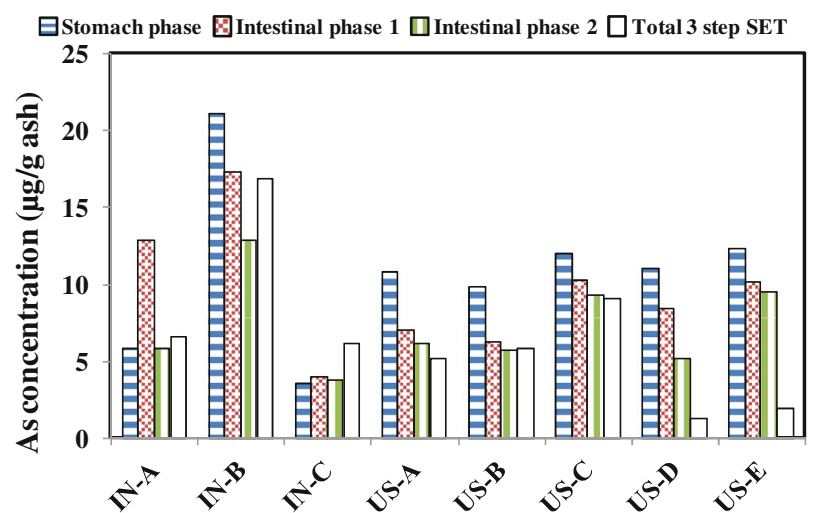

(a)

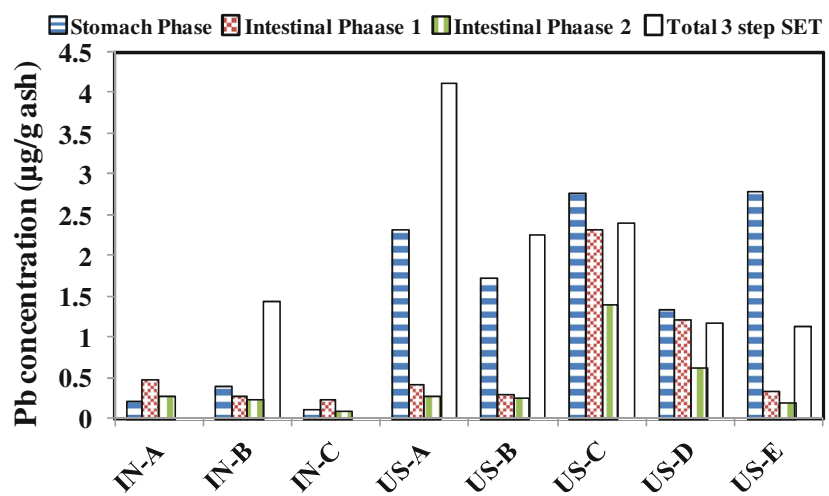

(c)

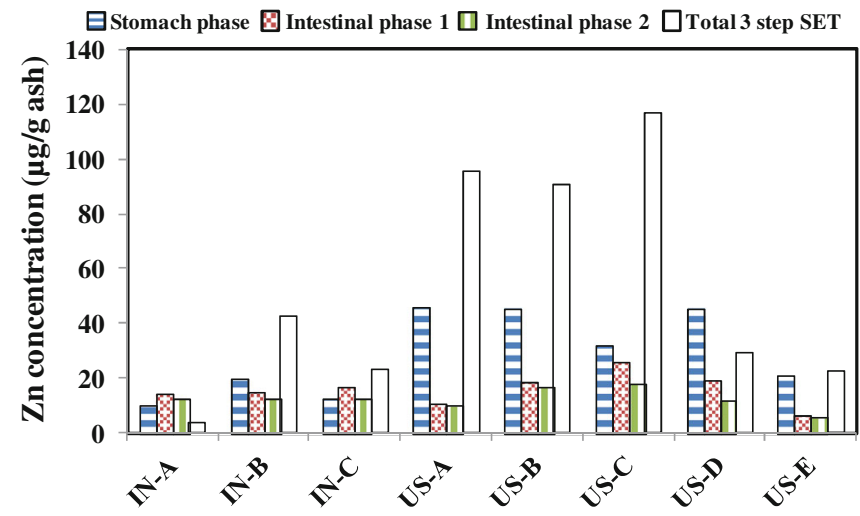

(e)

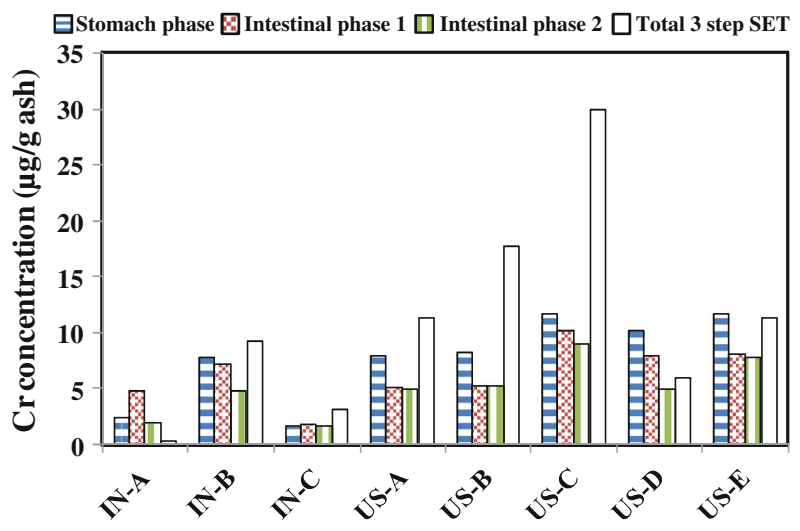

(b)

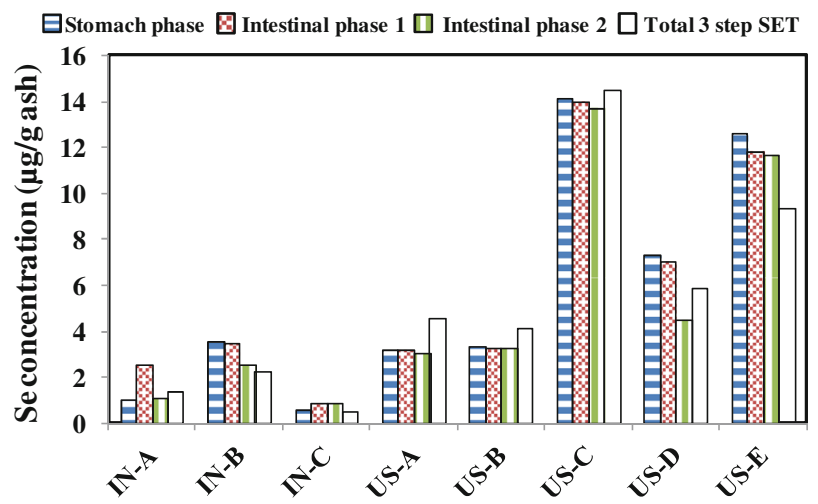

(d)

Fig. 4 The amount of $\mathbf{a}$ arsenic, $\mathbf{b}$ chromium, $\mathbf{c}$ lead, $\mathbf{d}$ selenium and $\mathbf{e}$ zinc extracted in stomach, intestinal phase 1, intestinal phase 2 and 3-step sequential extraction procedures

in the acidic environment and then in the intestinal phase where pancreatin and bile salts were added and the $\mathrm{pH}$ of the solution was increased to neutral condition, the leaching of $\mathrm{Pb}$ in the intestinal phase was decreased.

In Ca-rich coal fly ash, metal leaching of $\mathrm{Pb}$ in the stomach phase was in the range of $0.4-3 \mu \mathrm{g} / \mathrm{g}$ of ash whereas the three-step SEP $\mathrm{Pb}$ leaching ranged between 1 and $4 \mu \mathrm{g} / \mathrm{g}$ of the ash (Fig. 4c), and between 24 and $44 \mu \mathrm{g} / \mathrm{g}$ of ash as total $\mathrm{Pb}$. The extractability of $\mathrm{Pb}$ leaching by PBET and SEP revealed that the huge amount of $\mathrm{Pb}$ leaching occurred in the SEP for the same solid-to-liquid ratio. In the case of Si-rich coal fly ash, minor quantities of 


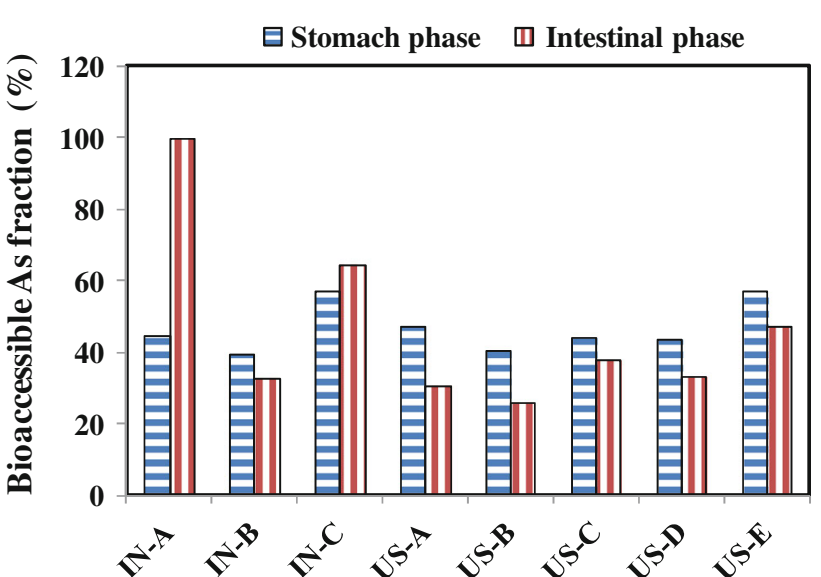

(a)

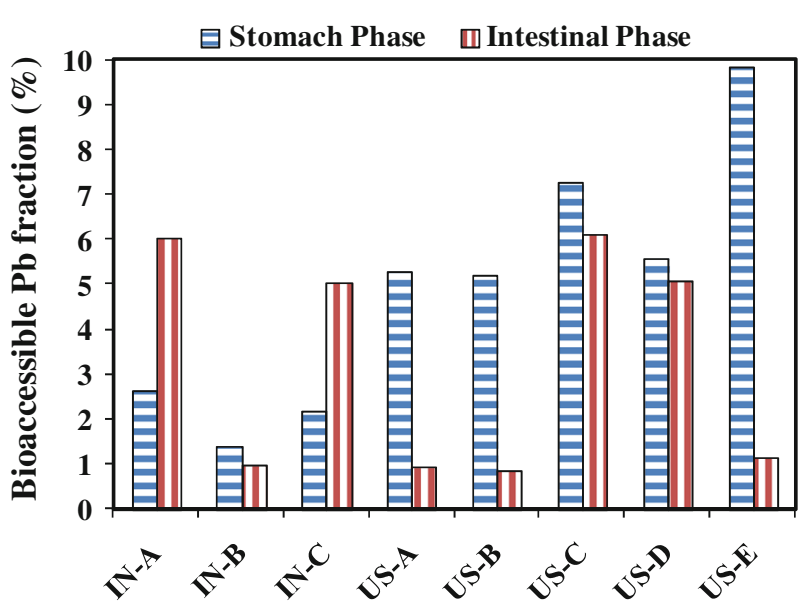

(c)

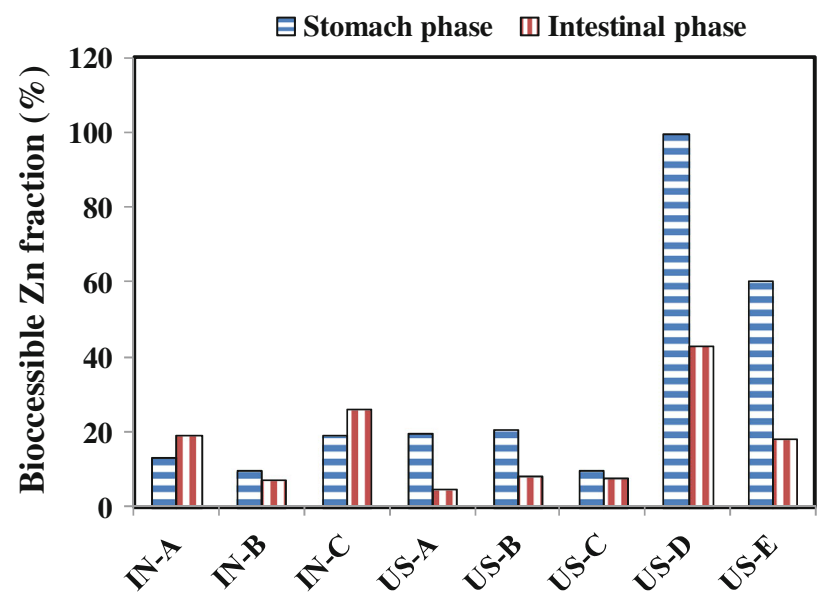

(e)

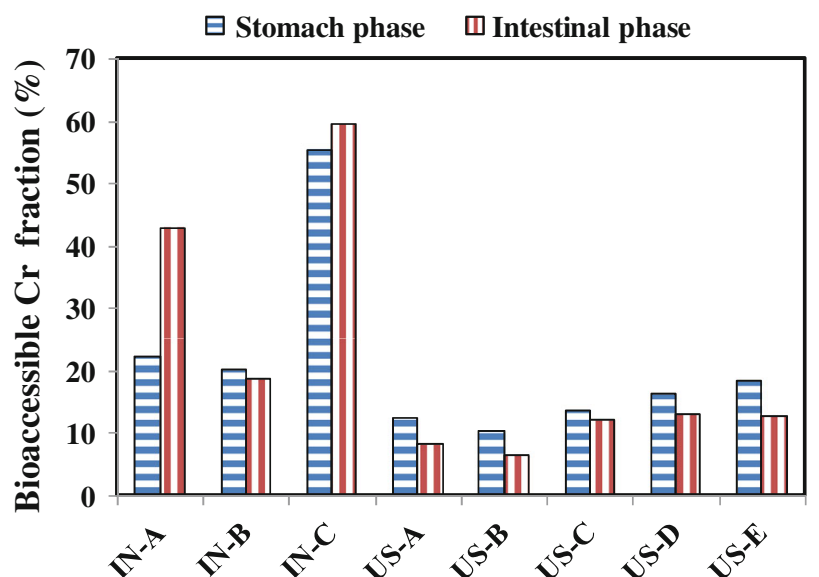

(b)

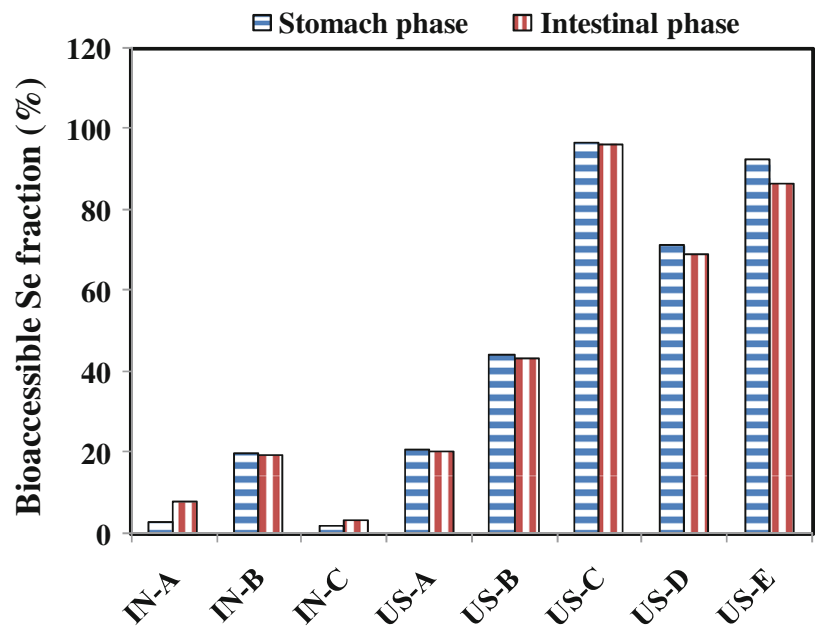

(d)

Fig. 5 Bioaccessible fraction of a arsenic, b chromium, $\mathbf{c}$ lead, $\mathbf{d}$ selenium and e zinc from various coal fly ash samples as determined by PBET

$\mathrm{Pb}$ leaching took place in the intestinal phase and were range between 0.2 and $0.5 \mu \mathrm{g} / \mathrm{g}$ of ash. The three-step SEP in the coal fly ash was zero, and the total $\mathrm{Pb}$ ranged between 5 and $8 \mu \mathrm{g} / \mathrm{g}$ of ash. The quantities of Pb leaching in the case of Si-rich coal fly ash in the intestine phase were ranged between 5 and $6 \%$. 


\section{Selenium}

During the PBET, considerable Se leaching took place in the stomach phase for the Ca-rich coal fly ash due to its leaching in acidic environment and the bioaccessible $\mathrm{Se}$ ranged from 20 to $97 \%$ (Fig. 4d). In Si-rich coal fly ash, the leaching occurred in the intestinal phase and it ranged from 3 to $8 \%$.

The 3-step SEP of Se in the case of Ca-rich coal fly ash was from 2 to $9 \mu \mathrm{g} / \mathrm{g}$ of ash whereas total Se ranged between 7 and $17 \mu \mathrm{g} / \mathrm{g}$ of ash. In the case of Si-rich coal fly ash, the three-step SEP Se extracted ranged from 0.5 to $1 \mu \mathrm{g} / \mathrm{g}$ of ash whereas the total Se ranged between 23 and $31 \mu \mathrm{g} / \mathrm{g}$ of ash.

More Se was extracted from the Ca-rich ashes (all five U.S. ashes and IN-B) than from the Si-rich ashes, although the Si-rich ashes (IN-A and IN-C) actually had the highest Se contents of the eight ashes studied (Table 1). The solid phase speciation of Se clearly influences the leachability of Se more than does the total Se content. The Se speciation is probably much different for the Si-rich ashes than for the $\mathrm{Ca}$-rich ashes. Because of the limited Se content of the Carich ashes, the X-ray absorption spectroscopy study could only determine that the Se was predominantly Se(IV) (Luo et al. 2011) and it could not provide additional structural information. The 3-step SEP was an excellent predictor of the Se that can be mobilized in the PBET and consequently TCLP measurements may provide a good estimate of Se bioaccessibility.

\section{Zinc}

Considerable $\mathrm{Zn}$ leaching took place in the acidic environment of the calcium-rich coal fly ash and ranged between 10 and $100 \%$ (Fig. 4e). In silica-rich coal fly ash, the $\mathrm{Zn}$ leaching occurred in the intestinal phase 1 of the neutral environment and ranged between 19 and $26 \%$. The three-step SEP of the calcium-rich coal fly ash ranged from 23 to $117 \mu \mathrm{g} / \mathrm{g}$ ash whereas the total $\mathrm{Zn}$ ranged from 34 to $333 \mu \mathrm{g} / \mathrm{g}$ of ash. In the case of silica-rich coal fly ash, the three-step SEP ranged between 3 and $23 \mu \mathrm{g} \mathrm{Zn/g}$ of ash whereas the total $\mathrm{Zn}$ ranged from 64 to $73 \mu \mathrm{g} / \mathrm{g}$ of ash.

The 3-step SEP extracted considerably more $\mathrm{Zn}$ than did the PBET for almost all of the Ca-rich ashes. For the Carich ashes, the amount of $\mathrm{Zn}$ remaining in the extractant decreased considerably in the stomach phase. Ashes IN-B and US-A, US-B and US-C had both the highest total Zn contents and the highest SEP extractable amounts of $\mathrm{Zn}$.

Bioaccessibility of metals

The fraction of the metals in the ashes that are bioaccessible as defined by Eq. (1) varied depending on the source of the ash, the element of the interest and the portion of the gastrointestinal tract (Fig. 5a-e). A portion of the bioaccessible fraction may then be bioavailable for uptake from the human gastrointestinal tract into the bloodstream. Arsenic in the ash was very bioaccessible with $40-57 \%$ of the total As being bioaccessible for the Ca-rich ashes and 64-100 \% for the Si-rich ashes. The bioaccessible fraction of Se was also very high for the most $\mathrm{Ca}$-rich ashes (20-97\%), but it was much lower (3-8\%) for the Si-rich ashes. In contract, the bioaccessible fraction of $\mathrm{Cr}$ was much lower for the Ca-rich ashes (10-20\%) than the Sirich ashes (43-59\%), but it should be noted that the $\mathrm{Cr}$ contents of the Si-rich ashes were much lower than those of the Ca-rich ashes. The $\mathrm{Zn}$ bioaccessible fractions were lower than $25 \%$ for most of the ashes, but two low $\mathrm{Zn} \mathrm{Ca}$ rich ashes did have much higher bioaccessible fractions.

The bioaccessible fractions were usually quite similar for the stomach phase and the intestinal phase. This was particularly true for Se which had nearly identical bioaccessible fractions for the stomach and small intestine phase. Arsenic was consistently more bioaccessible in the stomach phase for the Ca-rich ashes, but it was more bioaccessible in the intestinal phase for both $\mathrm{Si}$-rich ashes. The bioaccessibility of As in the Ca-rich ashes may be influenced more by $\mathrm{pH}$ differences between the stomach and intestinal phases than in the Si-rich ashes. Similarly, the Cr bioaccessible fractions were slightly higher in the stomach phase for all of the $\mathrm{Ca}$ rich ashes but lower for the two Si-rich ashes. The behavior of $\mathrm{Zn}$ was most variable with respect to bioaccessibility with no consistent trends based on ash type. $\mathrm{Pb}$ was bioaccessible for $\mathrm{Si}$ - rich fly ashes ranged from 5 to $6 \%$ and for $\mathrm{Ca}$-rich fly ashes it ranged from 1 to $10 \%$.

\section{Conclusion}

Elements posing the greatest risks will be those with both high concentrations in the ash and large proportions of the element in bioaccessible forms. The results of the present study suggest that while As has relatively low concentrations in the ash, the fraction of the As that is bioaccessible can be quite high. Similarly, for $\mathrm{Se}$ in Ca-rich class $\mathrm{C}$ ashes, although Se contents may not be very large, most of the Se can be bioaccessible. In contrast, while the $\mathrm{Zn}$ contents of the ash were high, the bioaccessible fractions were low relative to those of Se and As. The solid phase speciation of the elements can strongly affect the bioaccessibility of the element; this is illustrated by the much lower Se bioaccessible fractions for the Si-rich class $\mathrm{F}$ ashes despite their having higher total Se contents than the class $\mathrm{C}$ ashes. The bioaccessibility of As and Se can make them the primary drivers of environmental risks associated with ash disposal. 
The PBET procedure can be an effective tool for assessing the bioaccessibility of different toxic metals in coal fly ash. For certain ashes and elements, the results with the PBET were considerably different from those with a 3-step SEP. In some cases, the TCLP provided a good measure or a conservative estimate of the physiologically extractable element (e.g., Se and $\mathrm{Cr}$ ). However, for other elements (e.g., As), the physiologically extractable amount of element was higher than that from the SEP and estimates of bioaccessibility based on the TCLP or SEP might underestimate the risk posed by arsenic in fly ash.

Acknowledgments The partial funding for the present research was provided by Clean Coal Consortium of McDonell Research Academy, Washington University, Saint Louis, USA.

\section{References}

Bruce S, Noller B, Matanitobua V, Jack N (2007) In vitro physiologically based extraction test (PBET) and bioaccessibility of arsenic and lead from various mine waste materials. J Toxicol Environ Health Part A 70:1700-1711

Dayan A, Paine A (2001) Mechanisms of chromium toxicity, carcinogenicity and allergenicity. J Human Toxicol 20:439-510

EPA (2008) EPA method 9200.1-86. Standard operating procedure for an in vitro bioaccessibility assay for lead in soil, pp 1-9

Hamel S, Buckley B, Lioy AJ (1998) Bioaccessibility of metals in soils for different liquid to solid ratios in synthetic gastric fluid. Environ Sci Technol 32(3):358-362

Huang SJ, Chang CY, Mui DT, Chang FC, Lee MY, Wang CF (2007) Sequential extraction for evaluating the leaching behavior of selected elements in municipal fly ash. J Hazard Mater 149:180-188

Kim DH, Park SJ, Lee DW, Lim HB, Hwang JY (2002) Speciation and sequential extraction of trace metals in incineration fly ash using IC and ICP-MS. J Liq Chromatogr RT 25(5):717-730

Kosson DS, Sloot VHA, Sanchez F, Garrabrants AC (2002) An integrated frame work for evaluating leaching in waste management and utilization of secondary materials. Environ Eng Sci 19(3):159-204

Lu SG, Chen YY, Shan HD, Bai SQ (2009) Mineralogy and heavy metal leachability of magnetic fractions separated from Chinese coal fly ashes. J Hazard Mater 169:246-255

Luo Y, Giammar DE, Huhmann BL, Catalano JG (2011) Speciation of selenium, arsenic, and zinc in class c fly ash. Energy Fuels 25(7):2980-2987

Mukherjee AR, Zevenhoven R, Bhattacharya P, Sajwan KS, Kikuchi R (2008) Mercury flow via coal and coal utilization byproducts: a global perspective. Resour Conserv Recycl 52:571-591

Navarro P, Arana G, Etxebarria N, Dean JR (2008) Evaluation of the physiologically extraction test as an indicator of metal toxicity in mussel tissue. Anal Chim Acta 622:126-132

Noel JD, Biswas P, Giammar DE (2007) Evaluation of a sequential extraction process used for determining mercury binding mechanisms to coal combustion byproducts. J Air Waste Manage Assoc 57:856-867
Popovic A, Djordjevic D (2009) pH dependent leaching of dump coal ash-retrospective environmental analysis. Energy Sources 31:1553-1560

Prakash K, Sridharan A (2009) Beneficial properties of coal ashes and effective solid waste management. J Pract Period Hazard Toxic Radioact Waste Manag 13(4):239-248

Rodriguez RR, Basta NT, Casteel SW, Pace LW (1999) An in vitro gastrointestinal method to evaluate bioavailable arsenic in contaminated soils and soil media. Environ Sci Technol 33(4):642-649

Roe BP, Klinck B (2007) Bioaccessibility of arsenic in mine contaminated soils: a case study from an abandoned arsenic mine in SW England (UK). J Environ Sci Health, Part A 42:1251-1261

Ruby MV, Davis A, Schoof R, Eberle S, Sellstone MC (1996) Estimation of lead and arsenic bioavailability using a physiologically based extraction test. Environ Sci Technol 30(2): 422-430

Ruby MV, Schoof R, Brattin W, Goldade M, Post G, Harnois M, Mosby DE, Casteel SW, Berti W, Carpenter M, Edwards D, Cragin D, Chappel W (1999) Advances in evaluating the oral bioavailability of inorganics in soil for use in human health risk assessment. Environ Sci Technol 33(21):3697-3705

Sialelli J, Urquhart GJ (2010) Use of physiologically based extraction test to estimate the human bioaccessibility of potentially toxic elements in urban soils from the city of Glasgow, UK. Environ Geochem Health 32(6):517-527

Singh G (2005) Environmental assessment of fly ash from some thermal power stations for reclamation of mined out areas. Fly ash utilization programme TIFAC, DST, New Delhi, IV, pp $9.1-9.10$

Smeda A, Zyrnicki W (2002) Application of sequential extraction and the ICP-AES method for study of the partitioning of metals in fly ashes. Microchem J 72:9-16

Sonmez O, Pierzynsk GM (2005) Phosphorus and manganese oxides effects on soil lead bioaccessibility: PBET and TCLP. J Water Air Soil Pollut 166(1-4):3-16

Thorneloe SA, Kosson DS, Sanchez F, Garrabrants AC, Helms G (2010) Evaluating the fate of metals in air pollution control residues from coal-fired power plants. Environ Sci Technol 44:7351-7356

Vassilev SV, Vassileva CG (2005) Methods for characterization of composition of fly ashes from coal fired power stations: a critical overviews. Energy Fuels 19:1084-1098

WGS (2011) Wyoming geological survey coal mines of the Powder River basin. http://www.wsgs.uwyo.edu/coalweb/WyomingCoal/ mines.aspx. Accessed 10 June 2011

Worathanakul P, Kongkachuichy P, Noel JD, Suriyawong A, Giammar DE, Biswas P (2008) Evaluation of nanostructured sorbents in differential bed reactors for elemental mercury capture. Environ Eng Sci 25:1061-1070

Wragg J, Cave MR (2002) In-vitro methods for the measurement of the oral bioaccessibility of selected metals and metalloids in soils: a critical review. R\&D Technical Report, pp 5-062/TR/001

Wragg J, Cave M, Nathanail P (2007) A study of the relationship between arsenic bioaccessibility and its solid phase distribution in soils from Wellingborough, UK. J Environ Sci Health, Part A 42:1303-1315 